\title{
Measurement of Mono Ethylene Glycol Volume Fraction at Varying Ionic Strengths and
}

\section{Temperatures}

\author{
Ammar Al Helal ${ }^{*+}$, Adam Soames ${ }^{*}$, Rolf Gubner ${ }^{*}$, Stefan Iglauer ${ }^{* *}$, Ahmed Barifcani ${ }^{*}$ \\ *WA School of Mines: Minerals, Energy and Chemical Engineering, Curtin University, Perth \\ W.A., Australia \\ **Petroleum Engineering Department, Edith Cowan University, Perth W.A., Australia \\ †Corresponding Author
}

\begin{abstract}
The estimation of MEG concentration is an essential criterion during the industrial regeneration of Mono-Ethylene Glycol (MEG) to evaluate the efficiency of the regeneration process and to control the concentration of MEG reinjected at the wellhead. Although many laboratory methods to determine MEG concentration exist, their application may be costly in terms of the time required to perform sampling and laboratory analysis. For this reason, an alternative method for determination of MEG concentrations has been proposed. This method can be performed on-site utilising physical properties that can be readily measured using portable measurement devices including refractive index $\left(n_{D}\right)$, electrical conductivity $(E C)$ and total dissolved solids (TDS).

The volume fraction $\left(F_{v m}\right), n_{D}, E C$, and TDS of MEG solutions have been measured at (283.15, 298.15, and 323.15) K, (10-100) vol. \%, and at $(0,0.125,0.25,0.5,1.0) \mathrm{M} \mathrm{NaCl}$ total volume of solution) ionic strength (IS). The experimental results were then correlated to develop a simplistic model capable of estimating the volume fraction of MEG mixtures at varying ionic strengths. The proposed models will therefore allow a quick and convenient method for the determination of MEG concentrations in the field to quickly identify undesirable changes in produced lean MEG concentration.
\end{abstract}

Keywords: MEG volume fraction; MEG Field measurement; MEG Regeneration; Refractive Index, Electrical conductivity; Ionic strength. 


\subsection{Introduction}

Hydrate inhibitors play a major role in sustaining the flow of hydrocarbon products within the transportation pipelines preventing the formation of natural gas hydrates (Brustad et al., 2005, Flaten et al., 2010, Lu et al., 2010, Latta et al., 2013, Mazloum et al., 2011, Kaasa et al., 2005). The oil and gas industry has recently begun to adopt the use of Mono-Ethylene Glycol (MEG) as an efficient gas hydrate inhibitor in place of the traditional hydrate inhibitors, including ethanol and methanol (AlHarooni et al., 2015, Brustad et al., 2005). Although MEG is more expensive, the switchover has occurred due to the ability to regenerate and reuse MEG following the hydrate inhibition process without significant changes in its inhibition properties, therefore, reducing operational costs (Zaboon et al., 2017, Brustad et al., 2005). Following the injection of MEG at the wellhead, it is separated onshore alongside the condensed water phase and subsequently regenerated to regain a typical purity above $80 \mathrm{wt}$ \% MEG (Zaboon et al., 2017, Halvorsen et al., 2007, Brustad et al., 2005). Furthermore, the regeneration process can be utilized to remove mineral ions and organic acids present in formation water and other process chemicals, including scale and corrosion inhibitors (Halvorsen et al., 2007, Flaten et al., 2010, Latta et al., 2013).

The measurement of the MEG concentration is an important criterion during the regeneration process to evaluate the efficiency of the distillation system and to control the MEG concentration injected into the pipeline (Zaboon et al., 2017, Sandengen, 2006, Sandengen and Kaasa, 2006). However, conventional methods of MEG concentration measurement during the operational process pose a significant challenge to plant operators (Sandengen, 2006, Sandengen and Kaasa, 2006). The main obstacles faced by the plant operators in accurately determining the concentration of MEG can be summarized as: 1) the time required to determine MEG concentration, which may involve shipping samples to an external laboratory for analysis, 2) the accuracy of the measurement after dilution to reach the limits of the testing devices, 3 ) the flexibility of the measurement process under different conditions, and finally, 4) the presence of mineral ions and impurities dissolved within the solution, which may cause inaccuracy of the measurement (Sandengen and Kaasa, 2006).

Numerous researchers have suggested the adoption of Karl Fischer's method for the determination of water content, and hence, the concentration of MEG (MacLeod, 1991, Meyer Jr and Boyd, 1959, Peters and Jungnickel, 1955, Scholz, 2012). While others have suggested using gas chromatography to measure the weight fraction of MEG (Porter and Auansakul, 1982, Bost and Sunshine, 1980, Sandengen, 2006, Sandengen and Kaasa, 2006). 
Recently, researchers have adopted a practical analytical method that combines different physical properties such as density, electrical conductivity, acoustic velocity and refractive index to measure the MEG concentration (Sandengen, 2006, Zafarani-Moattar and Tohidifar, 2008, Moosavi et al., 2013, Kolská et al., 2016, Fogg et al., 1955, Sandengen and Kaasa, 2006, Bonyad et al., 2011).

Unfortunately, a common conclusion is that there is a deviation in accuracy when measuring the physical properties of MEG/water mixture in the presence of impurities, which represents a fundamental limitation for accurate MEG measurement in the field (Sandengen and Kaasa, 2006). These impurities such as mineral ions, organic materials, and micro bubbles might cause a deviation in the measurement of different parameters of MEG solution such as refractive index, density, color, and viscosity (Sandengen, 2006, Moosavi et al., 2013, Wiederseiner et al., 2011). The measurement deviation may occur due to mineral ion interaction resulting in the changing of solution color, viscosity or immiscibility of other compounds in the MEG/water mixture (Sandengen, 2006, Sandengen and Kaasa, 2006). In general, we can conclude that the refractive index, density, and electrical conductivity are functions of dissolved impurities in the aqueous solution and have a significant influence upon the accuracy of analytical methods.

The physical properties of MEG solutions have been investigated by several researchers to investigate the influence of temperature on these parameters. For instance, Yang et al. (2003) studied the physical properties of water/MEG mixtures, such as, density, viscosity, and heat capacity over the temperature range of 298.15 to $378.15 \mathrm{~K}$. Furthermore, Moosavi et al. (2013) investigated the thermophysical properties of polyethylene glycol at different temperatures. Similarly, Trimble and Potts (1935) studied the relationship between the volume fractions of water/MEG versus the refractive index parameter. However, previous studies did not investigate the impact of different levels of salt content on the physical properties of MEG/water solutions. In summary, any physical property measurements of the mixture solutions in a pure state will be ideal measurements and cannot simulate the actual solutions experienced within industrial processes.

To measure the volume fraction of MEG solutions in the presence of salt ions, several different physical properties can be utilized as an alternative measurement method. For example, refractive index is an essential physical property of a solution that describes how light propagates through a medium and is determined by its composition (Booser, 1993, Aly and Esmail, 1993). However, the refractive index of a solution may be influenced by the presence 
of salt ions leading to inaccurate measurements and thus must be accounted for (Chiao and Thompson, 1957, Trimble and Potts, 1935, Sandengen, 2006, Booser, 1993, Kolská et al., 2016). It was found that commercial devices that have adopted the refractive index to measure the volume fraction of MEG such as the ATAGO PAL-91S device were not designed for accurate measurements in the presence of salts due to instrument operating condition limits. However, the total salinity of a solution can be reasonably predicted using portable measurement devices to estimate the electrical conductivity or total dissolved solids. As a result, these parameters can be theoretically fitted to a mathematical model to measure the corrected MEG volume fraction in regeneration plants at different salinity levels.

Furthermore, several commercially available in-line sensors and other devices have been developed to measure the concentration of ethylene glycol solutions (Bonyad et al., 2011, 2017). However, inline monitoring devices are often expensive and require regular calibration and maintenance to ensure accuracy. Common industrial contaminants, particularly mud and waxy materials as well as inorganic scaling products can limit the long-term accuracy of such systems if regular cleaning is not performed.

The objective of this study is, therefore, to generate empirical relationships capable of predicting the correct volume fraction of $\operatorname{MEG}\left(F_{v c}\right)$ by utilizing different physical parameters that can be quickly measured in the field, such as refractive index $\left(n_{D}\right)$ in combination with either electrical conductivity $(E C)$ or total dissolved salt $(T D S)$. Furthermore, the proposed models take into account changes in temperature over a range of $(283.15$ - 323.15) $\mathrm{K}$ and different ionic strengths over a range of $(0.0$ - 1.0) $\mathrm{M} \mathrm{NaCl}$ of total solution. These parameters can be obtained directly either in a laboratory or within the field by using conventional industrial devices, thus allowing quick and accurate concentration measurements. Additionally, the measured volume fractions of $\mathrm{MEG}\left(F_{v m}\right)$ have been corrected by considering water/alcohol miscibility to give an accurate reading of MEG volume fraction in water mixtures $\left(F_{v m c}\right)$.

\subsection{Experimental Equipment and Chemicals}

\subsection{Equipment}

To measure the physical properties of MEG solutions at varying temperatures and salinity levels, three hand-held laboratory devices were acquired from the ATAGO Company. The ATAGO PAL-BX/RI instrument was utilized to measure the refractive index of test solutions and the PAL-EC instrument was used to measure $E C$ and $T D S$ at lower ionic strengths. Due to 
the measurement limitations of the PAL-EC device at high ionic strengths, the $E C$ at high ionic strength was measured using a GMH 5450 instrument. TDS was calculated at a high ionic strength according to the relationship between TDS and EC (refer to Table 1). Both electrical conductivity devices were calibrated with a standard aqueous $\mathrm{KCl}$ solution having a conductivity of $50.00 \mathrm{mS} / \mathrm{cm}( \pm 0.5 \mathrm{mS} / \mathrm{cm})$ at a temperature of $298.15^{\circ} \mathrm{C}$.

The PAL-91S device was employed to measure the volume fraction of MEG $\left(F_{v m}\right)$. The measured volume fraction of MEG represents an uncalibrated value that deviated significantly if any dissolved salts were present. The PAL-91S device was designed to measure the volume fraction of MEG without taking into account the effect of dissolved salts or other impurities. In other words, this device was intended to measure the volume fraction of MEG solution under ideal conditions where zero salts were present. Two boundaries must be taken into the account when testing MEG samples with ATAGO devices. Firstly, when measuring any sample the maximum temperature cannot exceed $348.15 \mathrm{~K}$ due to instrument operating condition limits. Secondly, the PAL-91S was intended to measure a maximum MEG volume fraction of $90 \%$. The temperature of the test solutions was measured by using a built-in temperature sensor in each device with an accuracy of $\pm 0.1^{\circ} \mathrm{C}$. The operating temperature parameter was adjusted in each test by using a Haake A28 cooling and heating water bath from Thermo Scientific with an accuracy $\pm 0.1^{\circ} \mathrm{C}$.

Table 1. Specifications of Measurement Devices

\begin{tabular}{llll}
\hline Device Name & Type of Measurement & Range & Accuracy \\
\hline PAL-BX/RI & Refractive Index, $n_{D}$ & $1.3306-1.5284$ & \pm 0.0003 \\
GMH 5450 & Electrical Conductivity, EC & $0-1000 \mathrm{mS} / \mathrm{cm}$ & $\pm 0.1 \%$ \\
& & & \\
PAL-EC & Electrical Conductivity, EC & $0-19.9 \mathrm{mS} / \mathrm{cm}$ & \pm 0.4 \\
& $T D S$ & $0-9950 \mathrm{ppm}$ & \\
PAL-91S & Ethylene Glycol Vol. $\%$ & $0-90 \%$ & $\pm 0.4 \%$ \\
\hline
\end{tabular}

\subsection{Chemicals}

The MEG solution and sodium chloride used within this study were sourced from ChemSupply, with a purity of 99.8 wt. \% and 99.5 wt. \%, respectively. Before being utilized, the sodium chloride was dried within an oven for 24 hours at $375.15 \mathrm{~K}$ to remove excess water to ensure a constant and accurate weight. To produce the MEG solutions, deionized water with an electrical resistivity of $18.2 \mathrm{M} \Omega . \mathrm{cm}$ was used for all experiments. 


\subsection{Experimental Methodology}

\subsection{Experimental Procedure:}

All solutions were prepared by volume, using an analytical micropipette supplied by Thermo Fisher with a measurement accuracy of $\pm 0.001 \mathrm{ml}$, using the procedure outlined in Section 3.2. The resultant solutions were stored in sealed plastic vials and subsequently mechanically shaken for two hours to produce completely homogenous solutions. Prior to taking measurements, the samples were maintained at the required temperatures within a controlled water bath. Once a stable temperature was reached, the solutions were analyzed by the devices listed in Table 1 to determine the solutions' $n D, E C, T D S$ and volume fraction at the adjusted temperature. All measurements were repeated three times to achieve good repeatability and accuracy of the readings.

\subsection{Preparation of Sample Solutions}

In order to prepare the solutions analyzed for this study, two initial stock solutions of $100 \mathrm{vol}$. $\%$ MEG and 100 vol. \% distilled water were prepared with $1 \mathrm{M}$ salt concentration $(\mathrm{NaCl}, 58.44$ gm in 1.0 liter of total volume solution). Thus, ionic strength will be a measure of all ions in solution (i.e., $\mathrm{NaCl}$ equivalents). Known volumes of each stock solution were then mixed to prepare ten samples with volume fractions ranging from 10 to $100 \mathrm{vol} \%$ in increments of 10 to obtain samples of known salt and MEG content. To produce samples of lesser salt molarity, the same procedure was repeated using fresh MEG and water stock solutions prepared with the new molarity. Table 2 outlines the solutions of varying ionic strengths and volume fractions of MEG that were tested by the listed devices below.

Table 2. Summary of Experimental Solutions

\begin{tabular}{cccc}
\hline $\boldsymbol{I S}, \boldsymbol{M}$ & $\boldsymbol{F}_{\boldsymbol{v i}, \text { Vol. } \%}$ & Temperature, $\mathbf{K}$ & Independent Parameters \\
\hline 1.00 & & & Refractive Index \\
0.50 & 10 to 100 & $283.15,298.15$, & Electrical Conductivity \\
0.25 & in increments of 10 & and 323.15 & $T D S$ \\
0.125 & & & $F_{v m}$ by PAL-91S \\
0.00 & & & \\
\hline
\end{tabular}

\subsection{Results and Discussions}

To ensure the accuracy of the testing procedure, an initial test was conducted using the refractive index measurement device listed in Table 1. The refractive index of varying concentration MEG solutions at $298.15 \mathrm{~K}$ along with their respective literature values are presented in Figure 1. The refractive index of MEG solutions measured within this study were 
found to be in good agreement with the literature data reported by Fogg et al. (1955) measured in weight fraction and Chu and Thompson (1960), of which was converted to volume fraction to facilitate the comparison as shown in Figure 1. The reported experimental data represents the average of 3-5 measurements with error bars indicated the standard deviation of the repeated measurements.

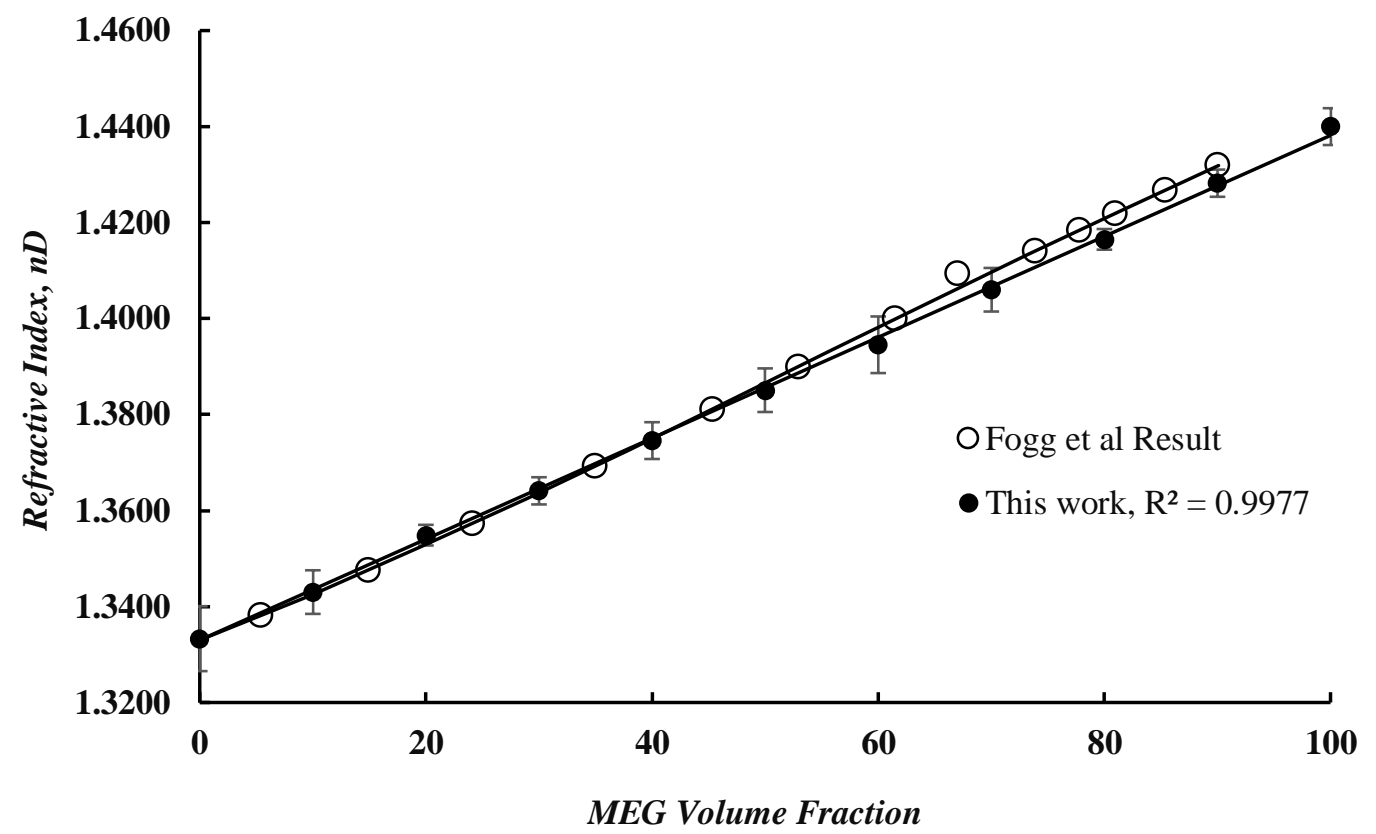

Figure 1. Refractive Index $\left(n_{D}\right)$ for this work and Fogg et al. (1955) as a function of MEG volume fraction at $298.15 \mathrm{~K}$.

\subsection{Application and Testing of the Experimental Data}

The electrical conductivity and refractive index of the prepared solutions were measured at varying ionic strengths and initial MEG volume fractions and are present by Figure 2, Figure 3 and Figure 4 respectively. The measurements were conducted to monitor the $\mathrm{NaCl}$ solubility behavior during the preparation of the sample solutions. When $\mathrm{NaCl}$ was present, a clear increase in electrical conductivity was observed with increasing $\mathrm{NaCl}$ content. Conversely, a decrease in electrical conductivity was measured with increasing MEG volume fraction at constant molarity, refer to Figure 2. These experimental results are in line with the findings of Sandengen and Kaasa (2006) who reported similar responses.

Furthermore, with increasing MEG volume fraction and $\mathrm{NaCl}$ molarity, an increase in the solutions refractive index was measured as per Figure 3, which is in line with the reporting of Zhou et al. (2010). It was noted that the influence of salinity on the refractive index readings was more pronounced at high salinity readings ( 0.25 to $1 \mathrm{M}$, Figure 2$)$ compared to low levels 
of salinity ( 0 to $0.25 \mathrm{M}$, Figure 4$)$. Therefore, using the refractive index solely as a measure of MEG volume fraction will provide inaccurate results when the concentration of mineral ions is high within the solution. Consequently, to accurately predict the volume fraction of MEG in the presence of mineral ions, a combination of the refractive index and a measure of the salt content such as electrical conductivity or total dissolved solids is required.

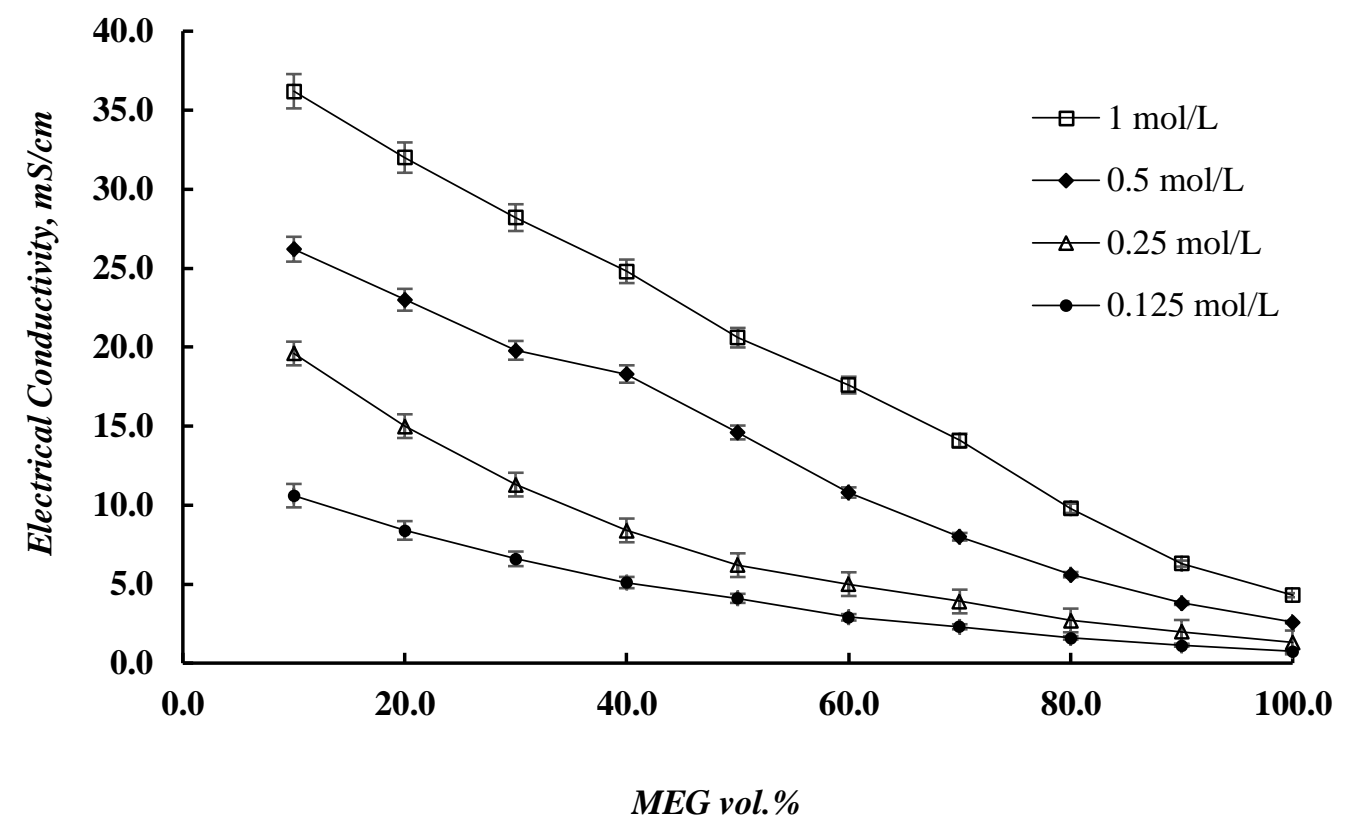

Figure 2. Electrical Conductivity $(E C)$ at a temperature of $298.15^{\circ} \mathrm{K}$ as a function of MEG volume fraction and $\mathrm{NaCl}$.

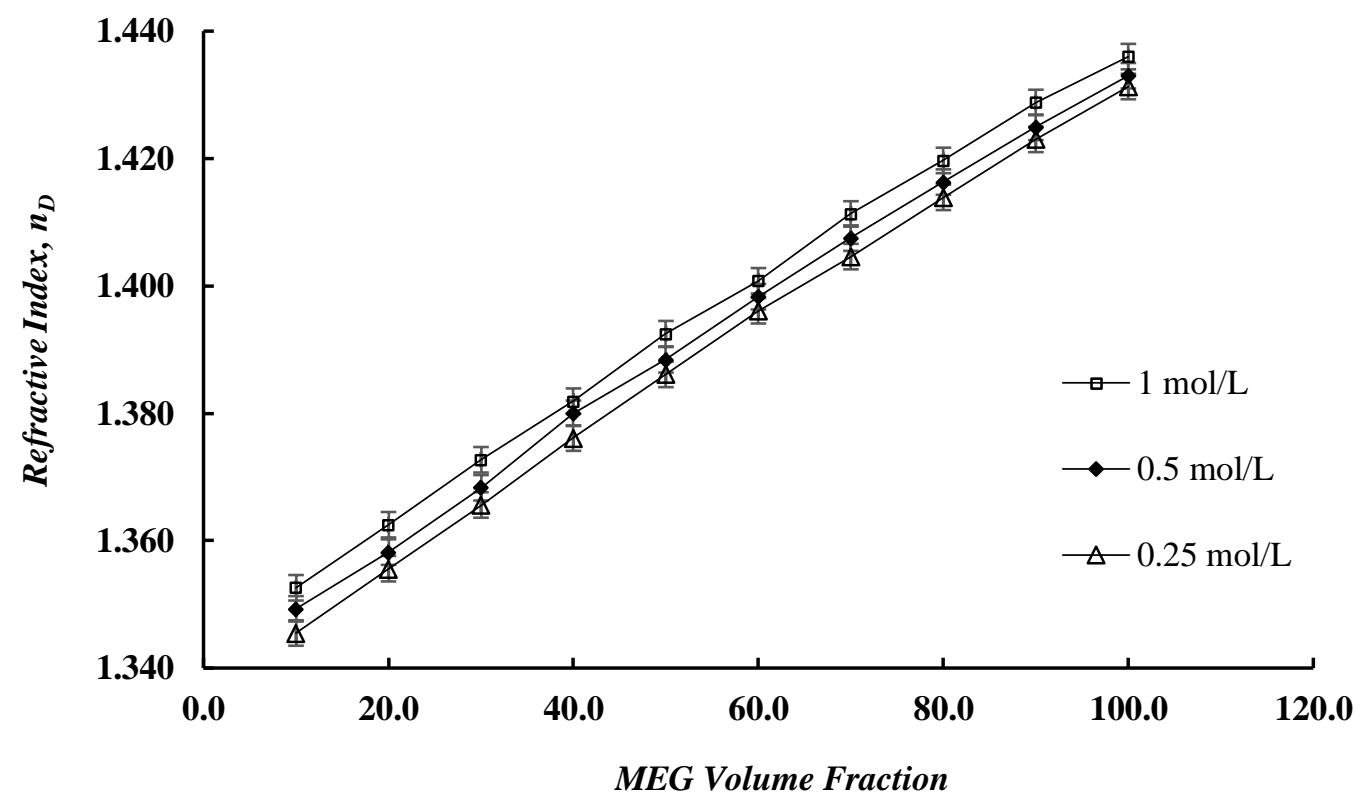

Figure 3. Refractive Index $\left(n_{D}\right)$ as a function of MEG volume fraction and ionic strength at $298.15^{\circ} \mathrm{K}$. 


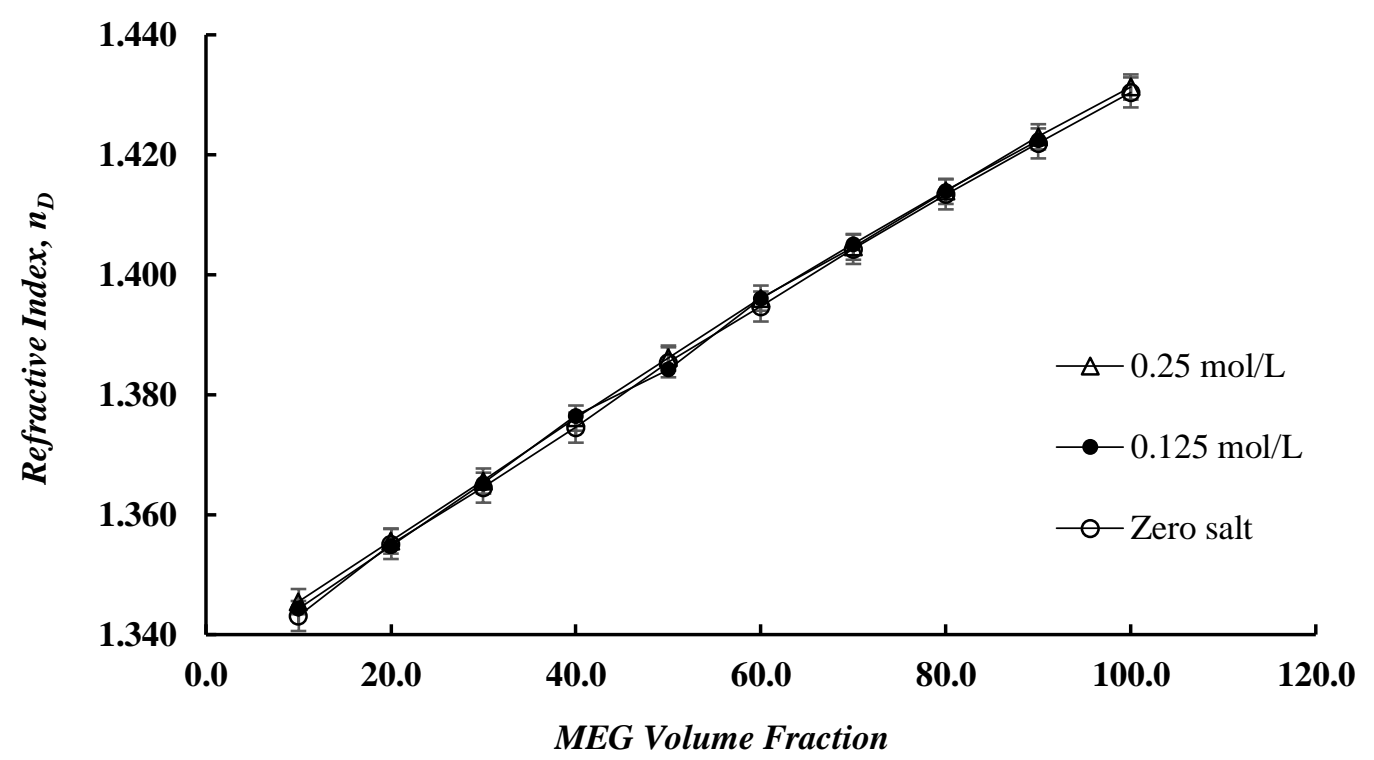

Figure 4 - Refractive Index $\left(n_{D}\right)$ as a function of MEG volume fraction and ionic strength at $298.15^{\circ} \mathrm{K}$.

\subsection{Effect of Ionic Strength on the MEG Volume Fraction Measurements}

The primary results of this study outlining the effect of ionic strength upon the refractive index $\left(n_{D}\right)$, Electrical Conductivity $(E C)$ and Total Dissolved Salts $(T D S)$ of varying volume fraction MEG solution are presented within Table 10 for ionic strengths of 1.0, 0.5, 0.25, and $0.125 \mathrm{M}$ of $\mathrm{NaCl}$ respectively. $\mathrm{NaCl}$ was chosen as the basis of ionic strength as the majority of mineral salt experienced within industrial MEG regeneration occurs as $\mathrm{NaCl}$. The values reported with respect to refractive index, $E C$ and $T D S$ represent the values measured by the measuring devices listed in Table 1 and were subsequently used to calculate the corrected volume fraction MEG, $F_{v c}$. Furthermore, the volume fraction of MEG, $F_{v m}$ measured by the PAL-91S device is reported. Definitions of the respective parameters used within each model are outlined by Table 3.

Table 3. Mathematical Model Nomenclature

\begin{tabular}{cr}
\hline Parameter Symbol & Definition \\
\hline$F_{v i}$ & Initial prepared volume fraction of MEG \\
$F_{v m}$ & Measured volume fraction using PAL-91S without correction \\
$F_{v c}$ & Calculated volume fraction of MEG as a function of salt content \\
$I S_{e}$ & Calculated ionic strength as a function of $n_{D}$ and $E C$. \\
$E C_{e}$ & Calculated electrical conductivity as a function of $T D S$. \\
\hline
\end{tabular}


Figure 5 and Figure 6 show the response of refractive index and the MEG volume fraction measured by using portable devices versus initial prepared volume fraction $\left(F_{v i}\right)$ for solutions at zero and one molar of $\mathrm{NaCl}$. The plots demonstrate that the presence of ionic species such as $\mathrm{NaCl}$ can deviate the volume fraction of MEG solution measurements. The results were obtained by measuring the refractive indexes and volume fraction of MEG $\left(F_{v m}\right)$ using the PAL-RI/Brix and PAL-91S devices respectively. The error bars associated with the measurements have been included indicating one standard deviation of the one molar measurements away from the respective zero molar measurements. It can be clearly recognized that the dissolved $\mathrm{NaCl}$ at one molar concentration has influenced the measurements of the refractive index in comparison to the zero-molar test solution. This result means that the dissolved salt has effectively increased the reading of the refractive index and subsequently the volume fraction of MEG reported by the measuring devices.

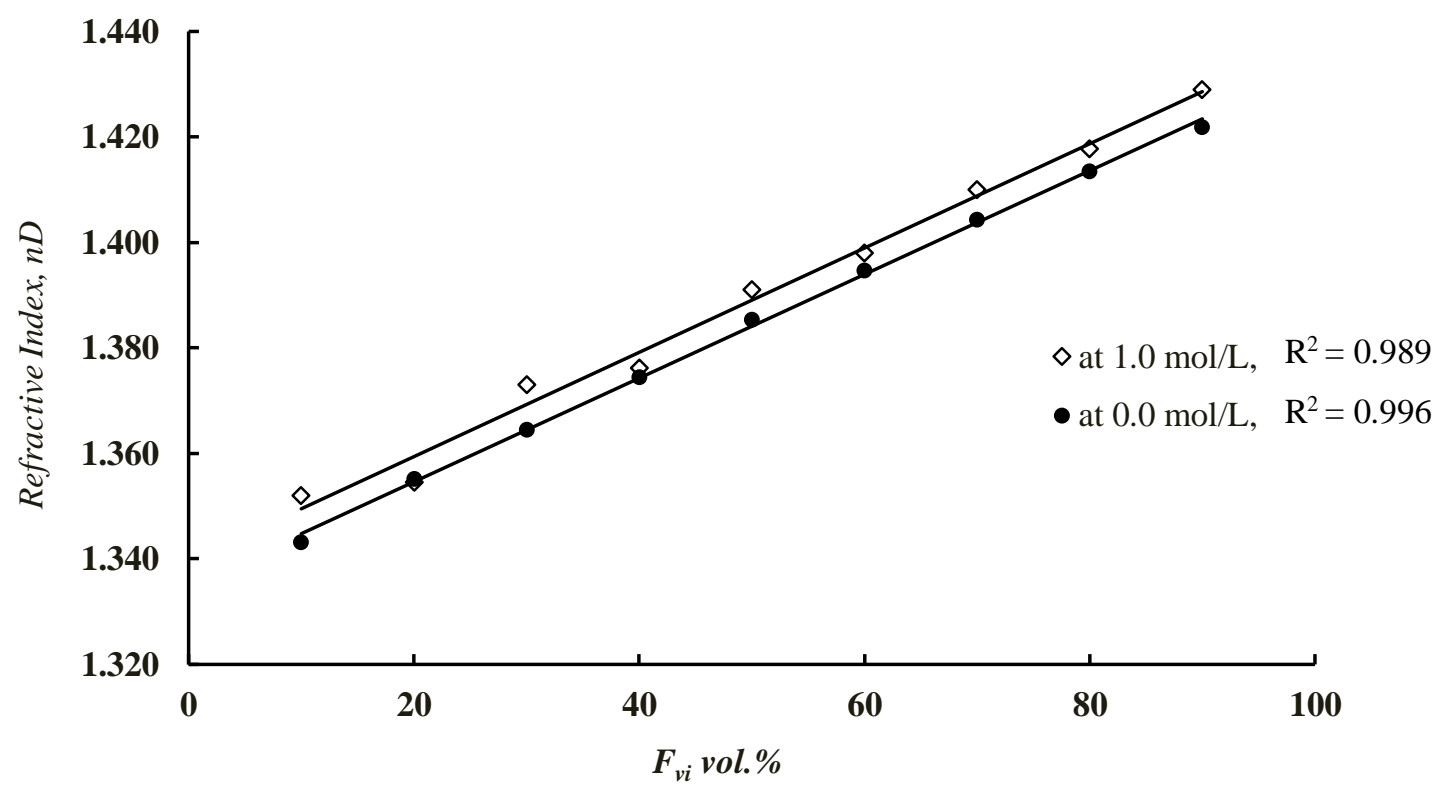

Figure 5. Effect of ionic strength on the refractive index measurements at $298.15 \mathrm{~K}$. 


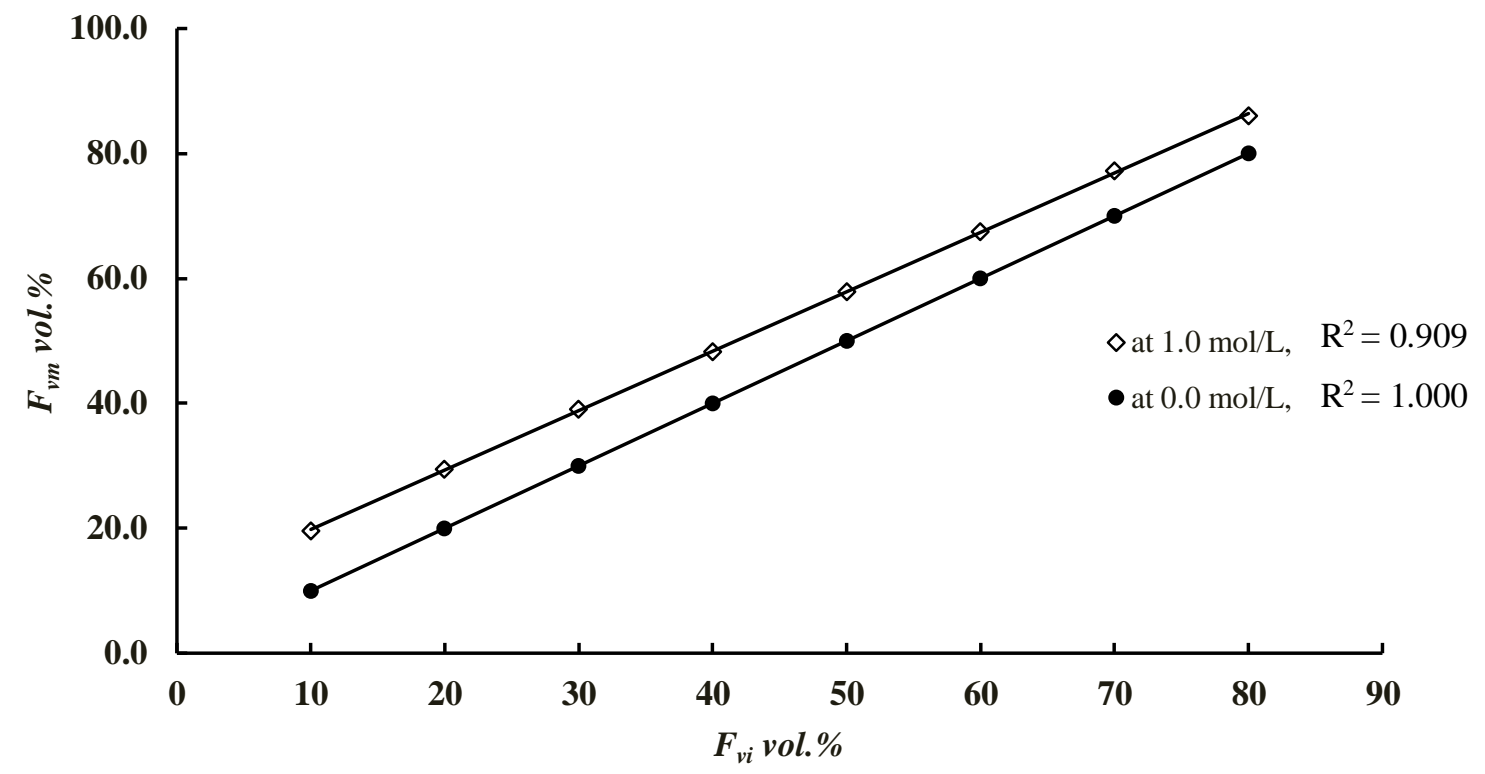

Figure 6. Effect of ionic strength on MEG volume fraction measurement at $298.15^{\circ} \mathrm{K}$.

\subsection{Correlation Analysis of Experimental Variables Using SPSS Statistics}

The polynomial model (Neter et al., 1996) described by Equation 1 was used to calculate the MEG volume fraction (dependent variable) by associating the field-readable variables (independent variables), such as refractive index, electrical conductivity, and uncorrected MEG volume fraction at different ionic concentrations. In addition, the same model was used to estimate the ionic strength of these solutions mathematically from values of MEG volume measured by the PAL-91S device and electrical conductivity.

$$
\begin{gathered}
Y=A_{0}+A_{1} * x+A_{2} * y+A_{3} * x^{2}+A_{4} * x * y+A_{5}+y^{2}+A_{6} * y * x^{2}+A_{7} * x * y^{2} \\
+A_{8} * y^{3}+A_{9} * x^{3}
\end{gathered}
$$

Where $Y$ denotes to the estimated MEG volume fraction or ionic strength, while $x$ and $y$ are denoted to independent values. $A_{0}$ to $A_{9}$ are model coefficient parameters.

By using a bivariate analysis tool (Reitsma et al., 2005, Opsomer and Ruppert, 1997), variables that have a mathematical correlation can be identified by determining the Pearson factor. The closer the Pearson factor is to 1.0, the more variables are affected by each other, and vice versa. The Pearson factor values are tabulated in Table 4, showing that the temperature parameter has a Pearson factor that is equal to approximately 0 , and can, therefore, be neglected. 
Table 4. Relationships between Experimental Variables by Using SPSS Statistics

\begin{tabular}{|c|c|c|c|c|c|c|c|}
\hline \multirow{2}{*}{\multicolumn{2}{|c|}{ Variables }} & \multicolumn{6}{|c|}{ Pearson Correlation } \\
\hline & & \multirow{2}{*}{$\begin{array}{c}\boldsymbol{F}_{\boldsymbol{v c}} \\
1.000\end{array}$} & \multirow{2}{*}{$\begin{array}{c}n_{D} \\
0.991\end{array}$} & \multirow{2}{*}{$\begin{array}{c}\boldsymbol{T} \\
0.000\end{array}$} & \multirow{2}{*}{$\begin{array}{c}\boldsymbol{E C} \\
-0.470\end{array}$} & \multirow{2}{*}{$\begin{array}{c}\boldsymbol{T D S} \\
-0.058\end{array}$} & \multirow{2}{*}{$\begin{array}{c}\boldsymbol{I S} \\
0.000\end{array}$} \\
\hline Dora & $F_{v c}$ & & & & & & \\
\hline уерепuетt & $I S$ & 0.000 & 0.085 & 0.001 & 0.501 & 0.501 & 1.000 \\
\hline \multirow{4}{*}{ Independent } & $n_{D}$ & 0.991 & 1.000 & -0.025 & -0.365 & 0.025 & 0.085 \\
\hline & $T$ & 0.000 & -0.025 & 1.000 & 0.037 & -0.102 & 0.001 \\
\hline & $E C$ & -0.470 & -0.365 & 0.037 & 1.000 & 0.557 & 0.501 \\
\hline & $T D S$ & -0.058 & 0.025 & -0.102 & 0.557 & 1.000 & 0.501 \\
\hline
\end{tabular}

\subsection{Corrected Volume Fraction of MEG as a Function of Refractive Index, Electrical Conductivity, and TDS}

To evaluate the effects of dissolved mineral salt ions upon the refractive index and hence measured volume fraction, the electrical conductivity of the test solutions was measured and incorporated into the proposed model. Electrical conductivity provides a measure of the total amount of ionic species $(\mathrm{NaCl})$ within the solution and is easily measured using portable devices which are readily accessible in industry or through inline measurement systems. The electrical conductivity of varying volume fraction MEG solutions at different $\mathrm{NaCl}$ concentrations are outlined within Table 10 and Figure 2 showing an increase in electrical conductivity occurring with higher $\mathrm{NaCl}$ concentrations. The proposed model outlined by Equation 2, corrects for the effect associated with the dissolved mineral salt ions when calculating the volume fraction of MEG from the measured refractive index. Comparison of initially prepared MEG fractions and those calculated by application of Equation 2 are presented in Table 10.

$$
\begin{gathered}
F_{v c}=A_{0}+A_{1} * n_{D}+A_{2} * E C+A_{3} * n_{D}^{2}+A_{4} * n_{D} * E C+A_{5} * E C^{2}+A_{6} * E C * n_{D}^{2} \\
+A_{7} * n_{D} * E C^{2}+A_{8} * E C^{3}+A_{9} * n_{D}^{3}
\end{gathered}
$$

Where, $F_{v c}$ denotes the corrected MEG volume fraction with the model coefficient parameters given in

Table 5. For solutions containing no ionic species, Equation 3 provides a more accurate estimation of the corrected volume fraction $\left(F_{v c}\right)$ with respect to refractive index.

$$
F_{v c}=343.352-826.909 * n_{D}+320.749 * n_{D}^{3} \quad \ldots 3
$$


Table 5. Values of Parameters of Equation 2

\begin{tabular}{|c|c|}
\hline Constants & Parameter Estimate \\
\hline $\mathrm{A}_{0}$ & 24449.441 \\
\hline $\mathrm{A}_{1}$ & -54357.031 \\
\hline $\mathrm{A}_{2}$ & 26.521 \\
\hline $\mathrm{A}_{3}$ & 39615.692 \\
\hline $\mathrm{A}_{4}$ & -35.637 \\
\hline $\mathrm{A}_{5}$ & 0.089 \\
\hline $\mathrm{A}_{6}$ & 11.693 \\
\hline $\mathrm{A}_{7}$ & -0.064 \\
\hline $\mathrm{A}_{8}$ & $-1.834 \mathrm{E}-05$ \\
\hline $\mathrm{A}_{9}$ & -9449.331 \\
\hline
\end{tabular}

To evaluate the accuracy of the proposed model (Equation 2), the corrected volume fraction $\left(F_{v c}\right)$ was calculated for varying MEG-water volume fraction solutions at ionic strengths ranging from 0.125 to 1.0 molar and compared to the initial prepared MEG concentrations. Comparison was made by calculating the residual error $\left(F_{v c}-F_{v i}\right)$, with the residual with respect to initial MEG concentration plotted in Figure 7 for ionic strengths of $0.125,0.25,0.5$ and 1.0 $\mathrm{M}$ respectively. The calculated volume fractions were found to be in close agreement with the corresponding initially prepared volume fractions with the residual error found to be typically less than 2.0 vol. \% of MEG with an average measurement error of $1.77 \%$ by volume. Furthermore, the calculated volume fraction for solutions, containing no dissolved salts estimated through Equation 3 is illustrated graphically in Figure 8.

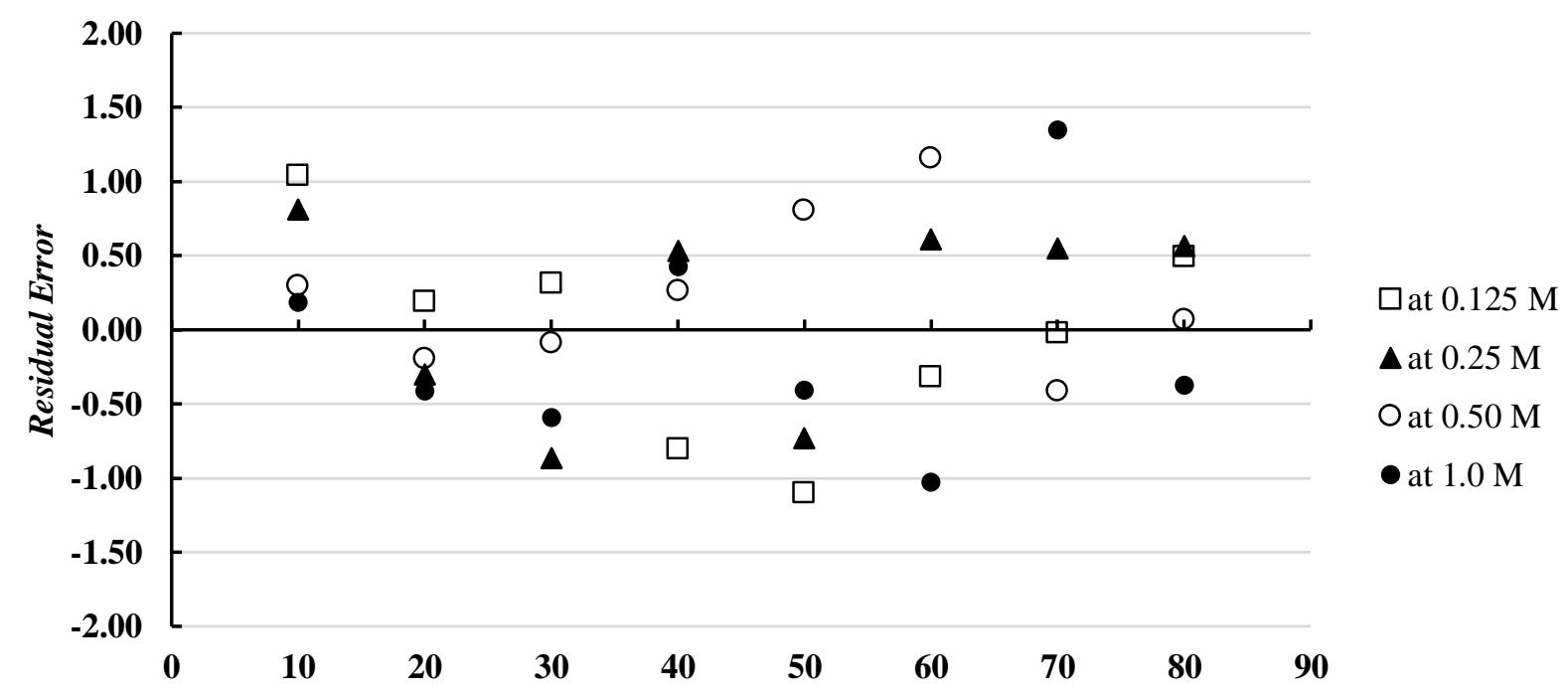

MEG Volume Fraction

Figure 7. MEG volume fraction residual error between actual and calculated values 


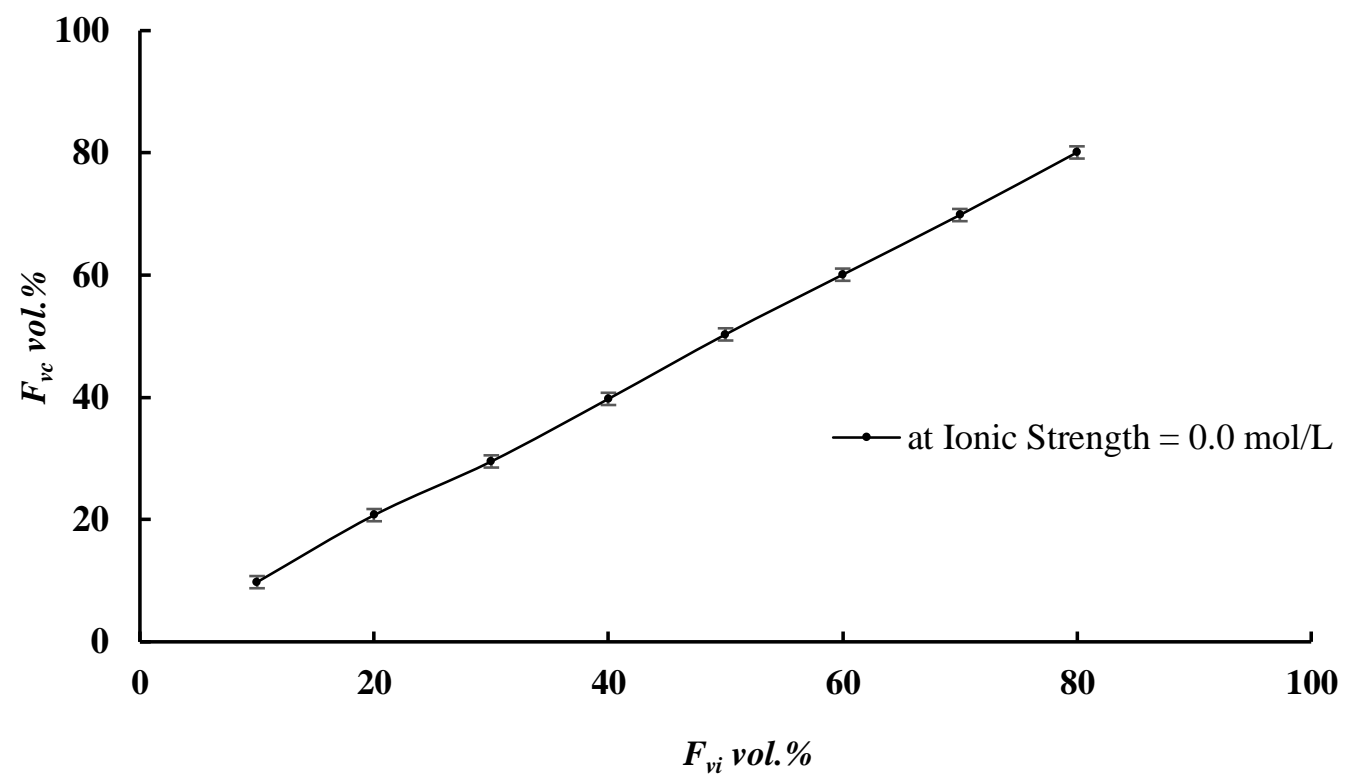

Figure 8. Estimated volume fraction of MEG solutions at no salt content, $\mathrm{R}^{2}=1.0$

Alternatively, the corrected volume fraction of MEG may also be calculated using a measure of the TDS within solution where electrical conductivity cannot otherwise be measured. The $T D S$ of a solution can be measured using commercially available hand-held measurement devices in a similar manner to electrical conductivity or using laboratory equipment. The corrected volume fraction of MEG can thus be estimated using the proposed model outlined by Equation 2 by first convert $T D S$ to $E C$. To allow application of $T D S$ measurements in place of $E C$, an empirical relationship was generated to convert the $T D S$ measurements to the equivalent $E C$ (Equation 4). The $F_{v c}$ of varying volume fraction solutions was calculated with respect to the measured TDS and is outlined within Table 10. Application of Equation 2 using TDS parameter as measurements of $E C$ produced similar accuracy as that obtained by Equation 2 when using measured $E C$, demonstrating that the $E C$ and $T D S$ can be used interchangeable (Walton, 1989) when estimating the corrected volume fraction of MEG.

$E C=\frac{T D S-0.004694}{500}$

\subsection{Correct Volume Fraction of MEG as a Function of Measured Volume Fraction, and Electrical Conductivity}

Furthermore, if the MEG volume fraction of the solution can be readily measured using a portable device similar to that of PAL-91S used within this study, the following model. The model described by Equation 5, utilizes the measured volume MEG fraction reported by the PAL-91S or alternative device representing the MEG volume fraction without taking into 
account the effects of dissolved salts within the mixture. However, it should be noted that the PAL-91S device used within this study to produce MEG volume fraction measurements is only capable of doing so up to volumetric measurements up to $90 \%$. The volume fraction of MEG measured by the portable device can then be corrected using the proposed model using electrical conductivity as a measure of dissolved salt content. The model covers a wide ranges of ionic strengths from 0.0 to $1.0 \mathrm{M}$. Figure 9 illustrates the application of the model and the resulting residual error at all $\mathrm{NaCl}$ molarities with the calculated values for all molarities summarized in Table 10. The average measurement error with corresponding of initially prepared volume fractions was found equal to $1.34 \%$ by volume.

$$
\begin{gathered}
F_{v c}=A_{0}+A_{1} * F_{v m}+A_{2} * E C+A_{3} * F_{v m}^{2}+A_{4} * F_{v m} * E C+A_{5} * E C^{2}+A_{6} * E C * F_{v m}^{2} \\
+A_{7} * F_{v m} * E C^{2}+A_{8} * E C^{3}+A_{9} * F_{v m}^{3}
\end{gathered}
$$

Table 6. Values of Parameters of Equation 5

\begin{tabular}{|c|c|}
\hline Constants & Parameter Estimate \\
\hline $\mathrm{A}_{0}$ & 0.833 \\
\hline $\mathrm{A}_{1}$ & 0.910 \\
\hline $\mathrm{A}_{2}$ & -0.177 \\
\hline $\mathrm{A}_{3}$ & 0.002 \\
\hline $\mathrm{A}_{4}$ & 0.000 \\
\hline $\mathrm{A}_{5}$ & 0.002 \\
\hline $\mathrm{A}_{6}$ & $-1.541 \mathrm{E}-5$ \\
\hline $\mathrm{A}_{7}$ & 0.000 \\
\hline $\mathrm{A}_{8}$ & $1.147 \mathrm{E}-7$ \\
\hline $\mathrm{A}_{9}$ & $-1.730 \mathrm{E}-5$ \\
\hline
\end{tabular}




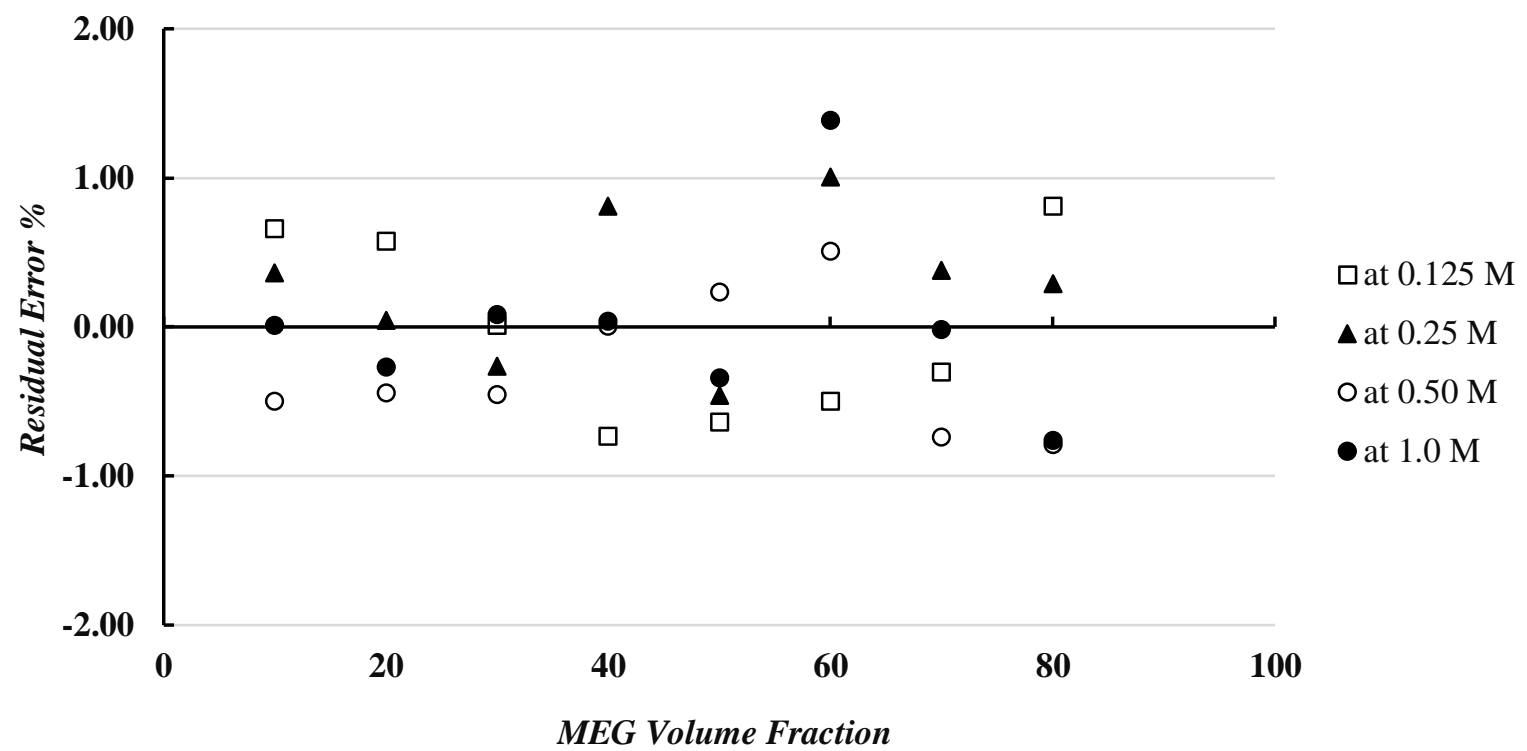

Figure 9. Residual error between the estimated and actual volume fraction of MEG solutions at ionic strength using measured volume fraction

\subsection{Solution Ionic Strength as a Function of Measured MEG Volume Fraction and Electrical Conductivity}

Unlike electrical conductivity or $T D S$, the ionic strength of a solution must be calculated or estimated via analytical means. The ionic strength of MEG solution can be accurately predicted using laboratory analytical techniques including Inductively Coupled Plasma (ICP) mass spectrometry however such analysis may take time to be performed (Ordoñez, 2015, Bhandari et al., 2015, Ambashta and Sillanpää, 2010). Alternatively, the electrical conductivity of the solution can be used as an essential parameter combined with the uncorrected measurements of MEG solution to predict the ionic strength using the model defined by Equation 6. Equation 6 represents a quick method for estimating the ionic strength of a MEG solution within the ionic strength range of 0.125 to $1.0 \mathrm{M}$ without the need for time-consuming laboratory analysis. The resultant residual error is presented in Figure 10 with the average error produced by Equation 6 being $6.6 \%$.

$$
\begin{gathered}
I S_{e}=A_{0}+A_{1} * F_{v m}+A_{2} * E C+A_{3} * F_{v m}^{2}+A_{4} * F_{v m} * E C+A_{5} * E C^{2}+A_{6} * E C * F_{v m}^{2} \\
+A_{7} * F_{v m} * E C^{2}+A_{8} * E C^{3}+A_{9} * F_{v m}^{3}
\end{gathered}
$$


Table 7. Values of Parameters of Equation 6

\begin{tabular}{|c|c|}
\hline Constants & Parameter Estimate \\
\hline $\mathrm{A}_{0}$ & 0.233 \\
\hline $\mathrm{A}_{1}$ & 0.003 \\
\hline $\mathrm{A}_{2}$ & -0.043 \\
\hline $\mathrm{A}_{3}$ & 0.000 \\
\hline $\mathrm{A}_{4}$ & 0.001 \\
\hline $\mathrm{A}_{5}$ & 0.003 \\
\hline $\mathrm{A}_{6}$ & $6.377 \mathrm{E}-06$ \\
\hline $\mathrm{A}_{7}$ & $-1.138 \mathrm{E}-05$ \\
\hline $\mathrm{A}_{8}$ & $-2.780 \mathrm{E}-05$ \\
\hline $\mathrm{A}_{9}$ & $1.833 \mathrm{E}-06$ \\
\hline
\end{tabular}

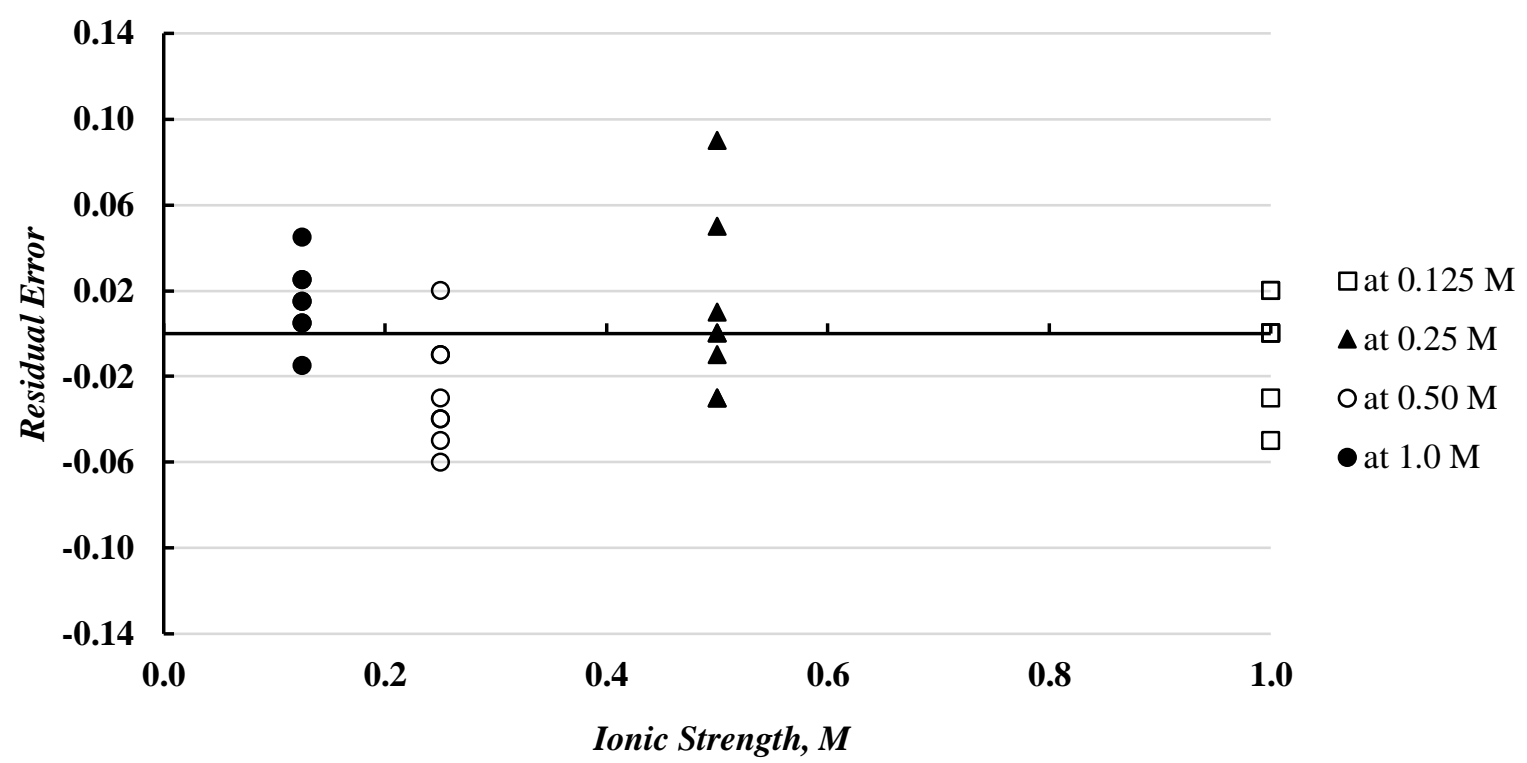

Figure 10. Ionic strength residual error between actual and estimated values of MEG volume fraction ranging from 10 to $80 \%$.

\subsection{Validation of Proposed Models}

To test the proposed models, a set of solutions was prepared with different MEG concentrations at different ionic strengths. The solutions were then analyzed in several ways to determine the volume fraction of MEG. The first method utilized was to completely evaporate the water from the salt containing MEG and the remaining MEG volume measured and compared to the known mass of water evaporated. This method was performed using a convection furnace at $90^{\circ} \mathrm{C}$ for two days. Secondly, Gas Chromatography (GC) was utilized to accurately determine the concentration of MEG within each solution.

Finally, the parameters of refractive index, electrical conductivity, and uncorrected volume fraction of MEG were measured by the measurement devices listed in Table 1. Table 8 represents the concentration values of the prepared solutions, while Table 9 describes the 
values derived from the respective laboratory tests and the proposed models. Comparison of corrected MEG concentrations compared to the concentrations determined by alternative analytical means showed good agreement. Therefore, the adoption of these models may provide a means of quickly and accurately determining the concentration of MEG solutions in the field.

Table 8 . Test Sample Solutions for Models Validation

\begin{tabular}{|c|c|c|c|c|}
\hline MEG vol. $\%$ & $\boldsymbol{n}_{\boldsymbol{D}}$ & $\boldsymbol{E} \boldsymbol{C}, \boldsymbol{m S} / \mathbf{c m}$ & PAL91S Measurements & $\boldsymbol{I S}, \boldsymbol{M}$ \\
\hline $80 \%$ & 1.4177 & 8.3 & $86.0 \%$ & 0.6850 \\
\hline $60 \%$ & 1.3980 & 11.3 & $64.2 \%$ & 0.5138 \\
\hline $40 \%$ & 1.3761 & 11.5 & $42.6 \%$ & 0.3425 \\
\hline $20 \%$ & 1.3546 & 11.7 & $21.6 \%$ & 0.1712 \\
\hline
\end{tabular}

Table 9 . Validation of Proposed Models

\begin{tabular}{|c|c|c|c|c|c|}
\hline Samples & $\begin{array}{c}\text { Boiling } \\
\text { Methods }\end{array}$ & $\begin{array}{c}\text { GC } \\
\text { Methods }\end{array}$ & $\begin{array}{c}\boldsymbol{F}_{\boldsymbol{v} \boldsymbol{c}} \\
\text { by Equation 2 }\end{array}$ & $\begin{array}{c}\boldsymbol{F}_{\boldsymbol{v} \boldsymbol{c}} \\
\text { by Equation 5 }\end{array}$ & $\begin{array}{c}\boldsymbol{I} \boldsymbol{S}_{\boldsymbol{e}} \\
\text { by Equation 6 }\end{array}$ \\
\hline $80 \%$ & $79.75 \%$ & $80.20 \%$ & $80.80 \%$ & $80.39 \%$ & $0.70 \mathrm{M}$ \\
\hline $60 \%$ & $60.10 \%$ & $60.15 \%$ & $60.25 \%$ & $60.46 \%$ & $0.51 \mathrm{M}$ \\
\hline $40 \%$ & $39.20 \%$ & $39.21 \%$ & $39.23 \%$ & $39.80 \%$ & $0.30 \mathrm{M}$ \\
\hline $20 \%$ & $19.21 \%$ & $19.25 \%$ & $19.37 \%$ & $19.37 \%$ & $0.17 \mathrm{M}$ \\
\hline
\end{tabular}

\subsection{Conclusions}

The presence of dissolved mineral ions within industrial MEG regeneration systems presents a major limitation to generate quick and accurate measurements of MEG volume fraction within the field. The purpose of this study was to generate models capable of accurately calculating the volume fraction of MEG when mineral salts are present using portable measuring devices that are easily accessible within the field allowing quick measurements to be made without extensive laboratory analysis. The proposed models utilize a combination of refractive index $\left(n_{D}\right)$ alongside either Electrical Conductivity $(E C)$, Total Dissolved Solids (TDS), Ionic Strength $(I S)$ or uncorrected volume fraction measurements $\left(F_{v m}\right)$ to incorporate the effects of dissolved salts. Experimental measurements of $n_{D}$ and $E C, T D S$ and $F_{v m}$ have been performed in varying volume fraction of $\mathrm{MEG}+$ water solutions in the presence of $\mathrm{NaCl}$, the most common mineral salt experienced during industrial MEG regeneration.

Through bivariate analysis, it was possible to demonstrate that temperature has no significant effect on the laboratory-read parameters. This is due to the fact that the laboratory devices used in this study are temperature compensating. Thus, the effect of temperature is eliminated during the generation of these mathematical models and the use of temperature compensated measurement devices. The developed models allow the accurate prediction of the corrected 
volumetric fractions of MEG $\left(F_{v c}\right)$, by using the measured refractive index and either $E C, T D S$ or $I S$ to correct the effects of $\mathrm{NaCl}$ at molarities ranging from 0.125 to $1.0 \mathrm{M}$. The proposed models were found to be most accurate when applied between volume fractions of 10-80 vol. $\%$ of brine/MEG solution with approximant average error of 1.7 vol. \%. Furthermore, ionic strength could be measured within acceptable accuracy at salt concentrations, ranging from 0.125 to $1.0 \mathrm{M}$ and with residual error of $0.078 \mathrm{M}$.

\subsection{Acknowledgments}

The authors would like to acknowledge Curtin Corrosion Engineering Industry Centre (CCEIC) and the Department of Chemical Engineering at Curtin University and Al-Khwarizmi collage of Engineering at Baghdad University for financial support. 


\subsection{Appendix}

Table 10 - Experimental Values for Refractive Index $\left(n_{D}\right), T D S, E C$, and Uncorrected Volume Fraction, and Estimated Values of MEG Volume Fraction and Ionic Strength for the Mono Ethylene $\mathrm{Glycol}+\mathrm{NaCl}+\mathrm{H}_{2} \mathrm{O}$ System

\begin{tabular}{|c|c|c|c|c|c|c|c|c|c|}
\hline \multirow{2}{*}{\multicolumn{2}{|c|}{$\begin{array}{l}\text { Dependent } \\
\text { Variables }\end{array}$}} & \multirow{2}{*}{\multicolumn{4}{|c|}{ Independent Variables }} & \multicolumn{4}{|c|}{ Estimated Parameters } \\
\hline & & & & & & \multicolumn{2}{|c|}{$F_{v c}$} & \multirow{2}{*}{$\frac{I S_{e}}{F_{v m}+E C}$} & \multirow{2}{*}{$\begin{array}{l}E C_{e} \\
T D S\end{array}$} \\
\hline IS & $F_{v c}$ & $n_{D}$ & $T D S$ & $E C$ & $\boldsymbol{F}_{v m}$ & $n_{D}+E C$ & $F_{v m}+E C$ & & \\
\hline 1.000 & 10.0 & 1.352 & 21172.50 & 42.345 & 19.600 & 11.043 & 10.661 & 1.02 & 42.345 \\
\hline 1.000 & 20.0 & 1.362 & 16666.50 & 33.333 & 29.400 & 20.190 & 20.576 & 0.95 & 33.333 \\
\hline 1.000 & 30.0 & 1.373 & 14533.50 & 29.067 & 39.000 & 30.316 & 30.012 & 0.97 & 29.067 \\
\hline 1.000 & 40.0 & 1.382 & 12900.00 & 25.800 & 48.267 & 39.198 & 39.266 & 1.00 & 25.800 \\
\hline 1.000 & 50.0 & 1.391 & 10900.00 & 21.800 & 57.800 & 48.902 & 49.360 & 1.00 & 21.800 \\
\hline 1.000 & 60.0 & 1.401 & 9216.50 & 18.433 & 67.533 & 59.684 & 59.501 & 1.02 & 18.433 \\
\hline 1.000 & 70.0 & 1.410 & 7416.50 & 14.833 & 77.200 & 69.981 & 69.700 & 1.00 & 14.833 \\
\hline 1.000 & 80.0 & 1.419 & 5617.00 & 11.234 & 88.133 & 80.491 & 80.811 & 1.00 & 11.234 \\
\hline 0.500 & 10.0 & 1.348 & 12966.50 & 25.933 & 15.200 & 10.814 & 10.362 & 0.50 & 25.933 \\
\hline 0.500 & 20.0 & 1.358 & 11166.50 & 22.333 & 25.333 & 19.697 & 20.044 & 0.50 & 22.333 \\
\hline 0.500 & 30.0 & 1.368 & 9733.50 & 19.467 & 35.133 & 29.136 & 29.739 & 0.51 & 19.467 \\
\hline 0.500 & 40.0 & 1.380 & 8900.00 & 17.800 & 46.533 & 40.532 & 40.810 & 0.59 & 17.800 \\
\hline 0.500 & 50.0 & 1.388 & 7283.50 & 14.567 & 54.667 & 49.270 & 49.540 & 0.55 & 14.567 \\
\hline 0.500 & 60.0 & 1.398 & 5266.50 & 10.533 & 65.333 & 60.609 & 61.003 & 0.49 & 10.533 \\
\hline 0.500 & 70.0 & 1.407 & 4016.50 & 8.033 & 74.467 & 70.551 & 70.379 & 0.47 & 8.033 \\
\hline 0.500 & 80.0 & 1.416 & 2816.50 & 5.633 & 84.467 & 80.565 & 80.288 & 0.47 & 5.633 \\
\hline 0.250 & 10.0 & 1.346 & 9666.65 & 19.333 & 12.933 & 10.296 & 9.504 & 0.27 & 19.333 \\
\hline 0.250 & 20.0 & 1.356 & 7400.00 & 14.800 & 22.933 & 19.805 & 19.558 & 0.24 & 14.800 \\
\hline 0.250 & 30.0 & 1.366 & 5550.00 & 11.100 & 32.533 & 29.910 & 29.547 & 0.22 & 11.100 \\
\hline 0.250 & 40.0 & 1.376 & 4200.00 & 8.400 & 42.600 & 40.262 & 40.005 & 0.21 & 8.400 \\
\hline 0.250 & 50.0 & 1.386 & 3100.00 & 6.200 & 52.467 & 50.804 & 50.234 & 0.19 & 6.200 \\
\hline 0.250 & 60.0 & 1.396 & 2500.00 & 5.000 & 62.733 & 61.157 & 60.509 & 0.20 & 5.000 \\
\hline 0.250 & 70.0 & 1.404 & 1950.00 & 3.900 & 71.600 & 69.586 & 69.260 & 0.21 & 3.900 \\
\hline 0.250 & 80.0 & 1.414 & 1366.50 & 2.733 & 82.000 & 80.066 & 79.212 & 0.24 & 2.733 \\
\hline 0.125 & 10.0 & 1.344 & 5300.00 & 10.600 & 11.867 & 10.184 & 10.009 & 0.11 & 10.600 \\
\hline 0.125 & 20.0 & 1.354 & 4266.50 & 8.533 & 21.733 & 19.585 & 19.732 & 0.14 & 8.533 \\
\hline 0.125 & 30.0 & 1.364 & 3350.00 & 6.700 & 32.000 & 29.406 & 30.082 & 0.15 & 6.700 \\
\hline 0.125 & 40.0 & 1.375 & 2650.00 & 5.300 & 41.800 & 40.423 & 40.038 & 0.15 & 5.300 \\
\hline 0.125 & 50.0 & 1.384 & 2166.50 & 4.333 & 51.333 & 49.594 & 49.657 & 0.14 & 4.333 \\
\hline 0.125 & 60.0 & 1.393 & 1600.00 & 3.200 & 63.067 & 58.973 & 61.385 & 0.13 & 3.200 \\
\hline 0.125 & 70.0 & 1.405 & 1133.50 & 2.267 & 71.800 & 71.349 & 69.981 & 0.13 & 2.267 \\
\hline 0.125 & 80.0 & 1.413 & 811.50 & 1.623 & 81.600 & 79.625 & 79.238 & 0.17 & 1.623 \\
\hline
\end{tabular}




\subsection{References}

In-line Brix-Monitor | In-line Ethyene Glycol Monitor | Products - refractometers, Brix meter, CM-780N, CM-780N-Plus, CM-780N-EG | ATAGO CO.,LTD. [Online]. Available: http://www.atago.net/product/?l=en \&f=products monitor.php\#CFc51688 [Accessed].

2017. Application - Water in Glycols - Keit Spectrometers [Online]. Available: https://keit.co.uk/irmadillo-water-glycols/ [Accessed].

ALHAROONI, K., BARIFCANI, A., PACK, D., GUBNER, R. \& GHODKAY, V. 2015. Inhibition effects of thermally degraded MEG on hydrate formation for gas systems. Journal of Petroleum Science and Engineering, 135, 608-617.

ALY, K. M. \& ESMAIL, E. 1993. Refractive index of salt water: effect of temperature. Optical Materials, 2, 195-199.

AMBASHTA, R. D. \& SILLANPÄ̈̈, M. 2010. Water purification using magnetic assistance: a review. Journal of hazardous materials, 180, 38-49.

BHANDARI, N., KAN, A. T., ZHANG, F., DAI, Z., YAN, F., LIU, Y., ZHANG, Z., BOLANOS, V., WANG, L. \& TOMSON, M. B. The Effect of Pressure and TDS on Barite Scaling Kinetics. SPE International Symposium on Oilfield Chemistry, 2015. Society of Petroleum Engineers.

BONYAD, H., MOSAYYEBI, M., MAZLOUM, S. \& TOHIDI, B. Field Evaluation of a hydrate inhibition monitoring system. Offshore Mediterranean Conference and Exhibition, 2011. Offshore Mediterranean Conference.

BOOSER, E. R. 1993. CRC Handbook of Lubrication and Tribology, Volume III: Monitoring, materials, synthetic lubricants, and applications, CRC Press.

BOST, R. O. \& SUNSHINE, I. 1980. Ethylene glycol analysis by gas chromatography. Journal of analytical toxicology, 4, 102-103.

BRUSTAD, S., LØKEN, K.-P. \& WAALMANN, J. G. Hydrate Prevention using MEG instead of $\mathrm{MeOH}$ : Impact of experience from major Norwegian developments on technology selection for injection and recovery of MEG. Offshore Technology Conference, 2005. Offshore Technology Conference.

CHIAO, T.-T. \& THOMPSON, A. 1957. Densities and Refractive Indices for Glycol-Water Solutions... Triethylene Glycol, Dipropylene Glycol, and Hexylene Glycol. Analytical Chemistry, 29, 1678-1681.

CHU, K.-Y. \& THOMPSON, A. 1960. Densities and Refractive Indices of Glycol Ether-Water Solutions. Journal of Chemical and Engineering Data, 5, 147-149.

FLATEN, E. M., SEIERSTEN, M. \& ANDREASSEN, J.-P. 2010. Induction time studies of calcium carbonate in ethylene glycol and water. Chemical Engineering Research and Design, 88, 1659-1668.

FOGG, E. T., HIXSON, A. N. \& THOMPSON, A. R. 1955. Densities and refractive indexes for ethylene glycol-water solutions. Analytical Chemistry, 27, 1609-1611.

HALVORSEN, A. M. K., ANDERSEN, T. R., HALVORSEN, E. N., KOJEN, G. P., SKAR, J. I., BIØRNSTAD, C. \& FITJE, H. The Relationship Between Internal Corrosion Control Method, Scale Control And Meg Handling Of A Multiphase Carbon Steel Pipeline Carrying Wet Gas With CO2 And Cetic Acid. CORROSION 2007, 2007. NACE International. 
KAASA, B., SANDENGEN, K. \& OSTVOLD, T. Thermodynamic predictions of scale potential, $\mathrm{pH}$ and gas solubility in glycol containing systems. SPE International Symposium on Oilfield Scale, 2005. Society of Petroleum Engineers.

KOLSKÁ, Z., VALHA, P., SLEPIČKA, P. \& ŠVORČÍIK, V. 2016. Refractometric study of systems water-poly (ethylene glycol) for preparation and characterization of $\mathrm{Au}$ nanoparticles dispersion. Arabian Journal of Chemistry.

LATTA, T. M., SEIERSTEN, M. E. \& BUFTON, S. A. Flow assurance impacts on lean/rich MEG circuit chemistry and MEG regenerator/reclaimer design. Offshore Technology Conference, 2013. Offshore Technology Conference.

LU, H., KAN, A. T. \& TOMSON, M. B. 2010. Effects of monoethylene glycol on carbonate equilibrium and calcite solubility in gas/monoethylene glycol/ $\mathrm{NaCl} /$ water mixed systems. Spe Journal, 15, 714-725.

MACLEOD, S. K. 1991. Moisture determination using Karl Fischer titrations. Analytical chemistry, 63, 557A-566A.

MAZLOUM, S., CHAPOY, A., YANG, J. \& TOHIDI, B. Online monitoring of hydrate safety margin. Proceedings of the 7th International Conference on Gas Hydrates (ICGH 2011), 2011. 17-21.

MEYER JR, A. \& BOYD, C. 1959. Determination of water by titration wth coulometrically generated Karl Fischer reagent. Analytical Chemistry, 31, 215-219.

MOOSAVI, M., MOTAHARI, A., OMRANI, A. \& ROSTAMI, A. A. 2013. Investigation on some thermophysical properties of poly (ethylene glycol) binary mixtures at different temperatures. The Journal of Chemical Thermodynamics, 58, 340-350.

NETER, J., KUTNER, M. H., NACHTSHEIM, C. J. \& WASSERMAN, W. 1996. Applied linear statistical models, Irwin Chicago.

OPSOMER, J. D. \& RUPPERT, D. 1997. Fitting a bivariate additive model by local polynomial regression. The Annals of Statistics, 186-211.

ORDOÑEZ, G. D. 2015. Geochemical kinetics during CO2 sequestration: the reactivity of the Hontomín caprock and the hydration of $\mathrm{MgO}$. Thesis.

PETERS, E. \& JUNGNICKEL, J. 1955. Improvement in Karl Fischer Method for Determination of Water. Analytical Chemistry, 27, 450-453.

PORTER, W. H. \& AUANSAKUL, A. 1982. Gas-chromatographic determination of ethylene glycol in serum. Clinical chemistry, 28, 75-78.

REITSMA, J. B., GLAS, A. S., RUTJES, A. W., SCHOLTEN, R. J., BOSSUYT, P. M. \& ZWINDERMAN, A. H. 2005. Bivariate analysis of sensitivity and specificity produces informative summary measures in diagnostic reviews. Journal of clinical epidemiology, 58, 982-990.

SANDENGEN, K. 2006. Prediction of mineral scale formation in wet gas condensate pipelines and in MEG (mono ethylene glycol) regeneration plants. Norwegian University of Science and Technology.

SANDENGEN, K. \& KAASA, B. 2006. Estimation of monoethylene glycol (MEG) content in water+ MEG+ $\mathrm{NaCl}+\mathrm{NaHCO} 3$ solutions. Journal of Chemical \& Engineering Data, $51,443-447$. 
SCHOLZ, E. 2012. Karl Fischer titration: determination of water, Springer Science \& Business Media.

TRIMBLE, H. \& POTTS, W. 1935. Glycol-water mixtures vapor pressure-boiling pointcomposition relations. Industrial \& Engineering Chemistry, 27, 66-68.

WALTON, N. 1989. Electrical conductivity and total dissolved solids-what is their precise relationship? Desalination, 72, 275-292.

WIEDERSEINER, S., ANDREINI, N., EPELY-CHAUVIN, G. \& ANCEY, C. 2011. Refractive-index and density matching in concentrated particle suspensions: a review. Experiments in fluids, 50, 1183-1206.

YANG, C., MA, P., JING, F. \& TANG, D. 2003. Excess molar volumes, viscosities, and heat capacities for the mixtures of ethylene glycol+ water from $273.15 \mathrm{~K}$ to $353.15 \mathrm{~K}$. Journal of Chemical \& Engineering Data, 48, 836-840.

ZABOON, S., SOAMES, A., GHODKAY, V., GUBNER, R. \& BARIFCANI, A. 2017. Recovery of mono-ethylene glycol by distillation and the impact of dissolved salts evaluated through simulation of field data. Journal of Natural Gas Science and Engineering, 44, 214-232.

ZAFARANI-MOATTAR, M. T. \& TOHIDIFAR, N. 2008. Vapor-liquid equilibria, density, speed of sound, and viscosity for the system poly (ethylene glycol) 400+ ethanol at different temperatures. Journal of Chemical \& Engineering Data, 53, 785-793.

ZHOU, Y., LI, S. N., ZHAI, Q., JIANG, Y. \& HU, M. 2010. Compositions, densities, and refractive indices for the ternary systems ethylene glycol+ $\mathrm{NaCl}+\mathrm{H} 2 \mathrm{O}$, ethylene glycol$+\mathrm{KCl}+\mathrm{H} 2 \mathrm{O}$, ethylene glycol$+\mathrm{RbCl}+\mathrm{H} 2 \mathrm{O}$, and ethylene glycol+ $\mathrm{CsCl}+\mathrm{H} 2 \mathrm{O}$ at 298.15 K. Journal of Chemical \& Engineering Data, 55, 1289-1294. 